\title{
LUBAC and ABIN-1 Modulate TRAIL-Based NF- $\kappa$ B Induction in Human Embryonic Kidney 293 Cells
}

\author{
Sebastian Dorn, ${ }^{1, *}$ Christian Schoergenhofer, ${ }^{1}$ Michael Krainer, ${ }^{2}$ Markus Müller, ${ }^{1}$ and Bernd Jilma
}

\begin{abstract}
Tumor necrosis factor (TNF)-related apoptosis-inducing ligand (TRAIL) is known to activate the canonical NF- $\kappa$ B pathway similar to TNF. The exact mechanism of the entire signaling cascade is still under investigation. The involvement of linear ubiquitylation as upregulating component has already been shown recently in some cell lines, but not in human embryonic kidney 293 (HEK293) cells. The downregulating function of the ABIN-1 (A20 binding and inhibitor of NF- $\kappa \mathrm{B}$ ) as linear ubiquitylation antagonist has been shown in combination with some NF- $\kappa \mathrm{B}$-inducing pathways, but not with TRAIL. We performed luciferase and western blot assays using HEK293 cells stimulated with either TRAIL (or TNF as a control) to analyze the involvement of linear ubiquitin chain assembly complex (LUBAC) components and the impact of $A B I N-1$ and ABIN-1-MAD (truncated form without A20 binding site) on NF- $\kappa$ B signaling. For overexpression experiments, we added plasmids of ABIN-1 and ABIN-1-MAD or LUBAC components HOIP, HOIL-1, or SHARPIN (single and combinations). For downregulation experiments five pairs of either SHARPIN, HOIL-1, or HOIP targeting miRNAs or one miRNA for ABIN-1 were designed and added. ABIN-1 and its truncated form ABIN-1-MAD reduced the $\mathrm{NF}-\kappa \mathrm{B}$ induction significantly indicating its involvement as antagonist (independent of deubiquitinase $\mathrm{A} 20$ ) of linear ubiquitylation in TRAlL-induced NF- $\kappa$ B signaling. In opposition, knockdown of ABIN-1 using a specific ABIN-1 miRNA led a clear increase of NF- $\kappa$ B signaling. Addition of single LUBAC components or combinations (except for SHARPIN with $\mathrm{HOIL}-1$ ) resulted in clearly stronger NF- $\kappa \mathrm{B}$ inductions. MiRNAs targeting LUBAC components significantly reduced NF- $\kappa$ B activation. Thus, in HEK293 cells linear ubiquitylation by LUBAC critically upregulates and ABIN-1 downregulates TRAlL-induced NF- $\kappa$ B signaling and may be interesting targets for future pathological therapies.
\end{abstract}

Keywords: ABIN-1; HEK 293 cells; NF- $\kappa$ B regulation; LUBAC; TRAIL

\section{Introduction}

Various regulator pathways and proteins exist that may influence apoptotic pathways that is, NF- $\kappa \mathrm{B}$, MAPkinases or inhibitor of apoptosis proteins (IAP proteins). ${ }^{1,2}$ The canonical NF- $\kappa \mathrm{B}$ pathway modulates the expression of apoptotic regulators which may support or inhibit cellular apoptosis. ${ }^{3}$ This pathway is activated by TNF, which leads to the assembly of the TNF receptor 1 (TNFR1)-associated signaling complex, containing TNFR-1, TRAF2, RIP1, cIAP $1 / 2$, and TRADD and the recruitment of $\mathrm{I} \kappa \mathrm{B}$ kinases IKK $\alpha$, IKK $\beta$, and IKK $\gamma$ (NEMO). ${ }^{1,4-6}$ The recruitment of these kinases is supported by the formation of Lys11and Lys63-based polyubiquitination chains, which serve as stable platforms.?

The E3 ligase linear ubiquitin chain assembly complex (LUBAC) consisting of the components SHARPIN, HOIL-1, and HOIP interacts with IKK $\gamma$ and ensures persistent NF- $\kappa \mathrm{B}$ activation. ${ }^{8-11}$ Among other functions, NF- $\kappa \mathrm{B}$ upregulates the antiapoptotic molecules c-FLIP(s), which directly inhibit the cleavage of the procaspase- 8 into its active form, and c-FLIP(L), which interferes with the release and maturation of caspase- 8 from the DISC. ${ }^{12-16}$ 
The TNF-related apoptosis-inducing ligand (TRAIL) also activates the NF- $\kappa$ B pathway in a similar way as TNF. When TRAIL binds to its receptors TRAILreceptor TRAIL-R1 or TRAIL-R2, the DISC consisting of FADD, RIP1, c-FLIP, cIAP1 and 2, Procaspase 8, and probably TRAF2 is rapidly assembled. ${ }^{17,18}$ Subsequently RIP1 is ubiquitylated by cIAP1/2. It accumulates within the DISC and is directly involved in the stimulation of NF- $\kappa \mathrm{B}$ signaling in combination with caspase- $8 .^{7,19,20}$ This pathway leads to the phosphorylation of IKK $\beta$ (and potentially IKK $\alpha$ ).

These similarities and the fact that in many tumor cells TRAIL-R1 and TRAIL-R2 are expressed at the cell surface led to the hypothesis that LUBAC could also be involved in TRAIL-based NF- $\kappa \mathrm{B}$ stimulation and could result in a stronger $\mathrm{NF}-\kappa \mathrm{B}$ induction. ${ }^{21}$ In combination with TRAIL-induced NF- $\kappa \mathrm{B}$ signaling, an antagonistic role of deubiquitinase A20 by destabilizing branched as well as linear polyubiquitylation chains associated with critical signaling components as RIP1 and NEMO and promoting RIP1 degradation performing ligase activity is under discussion. ${ }^{22}$ These potential functions make it to a key factor in NF- $\kappa \mathrm{B}$ signaling inhibition.

In comparison in TNF signaling ABIN-1 can potentially act as efficient NF- $\kappa$ B signaling inhibitor either indirectly as adaptor for $\mathrm{A} 20^{23,24}$ or directly by binding to polyubiquitylated chains preventing binding of RIP1, NEMO, or TRAF6 and NF- $\kappa$ B upregulation. ${ }^{25}$ These features and its ability to bind highly specific to linear ubiquitylation chains may make it to an attractive player in TRAIL-induced NF- $\kappa$ B signaling.

Since an involvement of LUBAC and of ABIN-1 and ABIN-1-MAD in TNF-induced NF- $\kappa \mathrm{B}$ signaling has been shown in human embryonic kidney 293 (HEK293) cells $^{25-28}$ and also the involvement of LUBAC in TRAILbased NF- $\kappa \mathrm{B}$ signaling in mouse embryonic fibroblasts, K562, HeLa, HCT116, MCF7, HT29, and A549 cells, ${ }^{29}$ we did our experiments in HEK293 cells. HEK293 cells are a very well-characterized cell line with features of kidney epithelial and adrenal gland cells, which has often been used as model for studying cancer-associated genes. ${ }^{30}$ Its immortalized status and ability to form tumors in mice after injection ${ }^{31}$ show its tumorigenic character and makes it to a good tumor in vitro cell model reflecting some important characteristics of tumor cells.

\section{Methods}

Luciferase assay

$0.3 \times 10^{4}$ HEK293 cells were seeded in poly-D-lysine (P6405-5 MG; Sigma) coated 96-well plates and incubated overnight. On the next day, the cells were trans- fected by using $0.1 \mu \mathrm{L}$ Turbofect (R0531; Fermentas) in $40 \mu \mathrm{L}$ serum-free medium and the reaction stopped after $2 \mathrm{~h}$. For overexpression experiments $75 \mathrm{ng}$ NF$\kappa \mathrm{B}$ responsive reporter (\#210978; Stratagene), $10 \mathrm{ng}$ pRL-CMV vector (E2261; Promega) in combination with 10,20 , or $30 \mathrm{ng}$ pCAGGS-E-hABIN-1 (LMBP $5126)$ or $10,20,30 \mathrm{ng}$ pCAGGS-E-hABIN-1-MAD (LMBP 5131) from BCCM or 10 ng HOIP-Myc, $10 \mathrm{ng}$ HA-HOIL-1, or 10 ng FLAG-SHARPIN (gifts from $\mathrm{K}$. Iwai) were cotransfected. As control, the plasmid pBluescript II KS (+) (\#212207; Stratagene) was used.

For downregulations, five pairs of oligonucleotides for SHARPIN, HOIL-1, and HOIP and one for ABIN-1 were designed (Life technologies; Supplementary Data) and cloned into POL II MIR RNAI GFP vectors (K493600; Life Technologies). For experiments in addition to $25 \mathrm{ng}$ of the reporter and $10 \mathrm{ng}$ of the Renilla luciferase expressing constructs, $100 \mathrm{ng}$ of the miRNA expression vectors were cotransfected and the GFP expressions were analyzed. As controls, the miRNA negative control vector (from K493600) and the pBluescript II KS (+) plasmid were used.

In all experiments, $48 \mathrm{~h}$ after, transfection media with $100 \mathrm{ng} / \mathrm{mL}$ TNF- $\alpha$ (T-6674-10UG; Sigma) or $1000 \mathrm{ng} /$ mL TRAIL (616374; Merck Chemicals) were added to the cells, and $24 \mathrm{~h}$ later, they were lysed and the expression levels of firefly luciferase and Renilla luciferase were analyzed by using the dual luciferase reporter assay system and the instructions from Promega (E1960) and the Victor $^{\mathrm{TM}}$ Multilabel Plate Reader (Perkin Elmer).

\section{Western blot}

$0.125 \times 10^{5}$ HEK293 cells were seeded on Poly-D-Lysinecoated six-well plates and transfected with $3 \mu \mathrm{g}$ Bluescript II KS vector, $3 \mu \mathrm{g}$ negative miRNA control plasmid as control or $3 \mu \mathrm{g}$ of the different SHARPIN, HOIP, HOIL-1, or ABIN-1 miRNA plasmids or $300 \mathrm{ng}$ of HOIP-Myc, HA-HOIL-1, FLAG-SHARPIN or $300 \mathrm{ng}$, $600 \mathrm{ng}$ or $900 \mathrm{ng}$ of pCAGGS-E-hABIN-1 or $300 \mathrm{ng}$, $600 \mathrm{ng}$ or $900 \mathrm{ng}$ of pCAGGS-E-hABIN-1-MAD by using $3 \mu \mathrm{L}$ Turbofect in $1.2 \mathrm{~mL}$ serum-free medium. Again to the cells $100 \mathrm{ng} / \mathrm{mL} \mathrm{TNF}-\alpha$ (for $30 \mathrm{~min}$ ) or $1000 \mathrm{ng} / \mathrm{mL}$ TRAIL (for $50 \mathrm{~min}$ ) was added after $48 \mathrm{~h}$. Subsequently, the cells were lysed by using a lysis buffer, containing PhosSTOP (0490683701; Roche) and protease inhibitor (04693116001; Roche), and the protein amounts were measured by Bradford assay, the proteins denatured and stored at $-80^{\circ} \mathrm{C}$.

The different protein expression levels were analyzed by using $5 \%$ stacking and $13 \%$ separating SDS-PAGE 
gels, PDVF membranes (W5601; Millipore), horseradish peroxidase detection reagents (32106; Thermo Scientific), and Hyperfilms (28-9068-40; Amersham). The stripping process was done in combination with restore Plus western blot stripping buffer (46430; Thermo Scientific). For the detection of the protein expressions, primary antibodies for SHARPIN (ab69507; Abcam), HOIP (ab85294; Abcam), HOIL-1 (ab38540; Abcam), ABIN-1 (ab70152; Abcam), I $\kappa$ B- $\alpha$ (sc-203; Santa Cruz), Phospho-I $\kappa \mathrm{B} \alpha$ (Ser32/36; \#9246; Cell Signaling), $\alpha$-Tubulin (\#2125; Cell Signaling), and $\beta$-Actin (\#8457; Cell Signaling) were used.

The intensity of the NF- $\kappa \mathrm{B}$ bands were normalized to the corresponding Actin or Tubulin signals, then the normalized signals were used to calculate fold induction, while with the negative control, vectortransfected samples were arbitrary set as 1 . For the band quantifications, the program Image Studio Lite version 5.2 was used.

\section{Results}

First, we examine the potential influence of ABIN-1 on TRAIL-induced NF- $\kappa$ B signaling. For this, HEK293 cells were transfected with a plasmid overexpressing ABIN-1 and stimulated with $1000 \mathrm{ng} / \mathrm{mL}$ TRAIL (TRAIL concentration was chosen according to observed stable NF- $\kappa \mathrm{B}$ induction in experiments being relevant for establishing possible resistance in HEK 293cells. ${ }^{32-35}$

Using a dual luciferase assay with a NF- $\kappa \mathrm{B}$ responsive reporter increasing amounts, ABIN-1 resulted in decreasing transcriptional NF- $\kappa \mathrm{B}$ activity (Fig. 1A). To test whether ABIN-1 can potentially downregulate TRAILinduced NF- $\kappa$ B signaling without A20 interaction, a truncated form of ABIN-1, ABIN-MAD (aa 441-601, was overexpressed, which is not able to interact with A20 anymore. Again a reduced NF- $\kappa \mathrm{B}$ signaling activity was observed with increasing amounts of plasmids of ABINMAD (Fig. 1A). In a subsequent experiment by using an ABIN-1-specific miRNA knockdown of ABIN-1 (for miRNA sequence see Supplementary Data) in combination with TRAIL, a clear increase of transcriptional NF$\kappa \mathrm{B}$ activity was observed (Fig. 1C).

Subsequently to these experiments $\mathrm{I} \kappa \mathrm{B} \alpha$ phosphorylation was analyzed by western blotting as a clear indicator of canonical NF- $\kappa \mathrm{B}$ activation. From literature, it is known that both $\mathrm{I} \kappa \mathrm{B} \alpha$ residuals 32 and 36 are phosphorylated in case of TNF addition being critical for $\mathrm{I} \kappa \mathrm{B} \alpha$ degradation and canonical NF- $\kappa \mathrm{B}$ induction. ${ }^{27}$ The phosphorylation of the same sites of $\mathrm{I} \kappa \mathrm{B} \alpha$ is also important for the TRAIL-based NF- $\kappa \mathrm{B}$ activation. According to luciferase experiments before, downregulation of $\mathrm{ABIN}-1$ resulted in an increase and overexpression of ABIN-1 in a clear reduction of $\mathrm{I} \kappa \mathrm{B} \alpha$ phosphorylation.

These results clearly indicate that ABIN-1 has the ability to inhibit TRAIL-based NF- $\kappa$ B signaling also without the deubiquitinase A20. Thus, since it is known that ABIN-1 binds strongly and specifically to linear ubiquitylation chains, an involvement of LUBAC in TRAILstimulated NF- $\kappa$ B signaling in HEK293 cells is likely. Lafont and colleagues showed that HOIP is critically involved in TRAIL-based NF- $\kappa$ B induction, but the roles of SHARPIN and HOIL-1 were not studied in detail. ${ }^{29}$ To test the hypothesis of LUBAC involvement and to investigate which of the LUBAC members, HOIP, HOIL-1, or SHARPIN, are most essential for NF- $\kappa$ B induction, we conducted further experiments.

In a first step as control, the several LUBAC members HOIP, HOIL-1, and SHARPIN were overexpressed without and with $100 \mathrm{ng} / \mathrm{mL}$ TNF (TNF concentration is a common amount to investigate an effect of TNF signaling components on TNF induction in HEK293 cells $^{33,36,37}$ to confirm known results that LUBAC is able to potentiate NF- $\kappa \mathrm{B}$ signaling upon TNF application (Fig. 2A). Similar to former publications, the application of each component alone led to no or weak $\mathrm{NF}-\kappa \mathrm{B}$ induction, but the combination of two or all three members (except SHARPIN with HOIL-1) resulted in a much stronger upregulation even without addition of TNF. ${ }^{9}$ In addition, the application of TNF in combination with the several LUBAC components showed further NF- $\kappa \mathrm{B}$ upregulation demonstrating that LUBAC is a key player in TNF-based NF- $\kappa \mathrm{B}$ activation.

The same experiments were repeated in combination with TRAIL to analyze whether and which LUBAC components are involved in TRAIL-based NF- $\kappa \mathrm{B}$ induction (Fig. 2B). Overexpression of the LUBAC members alone led to no or weak NF- $\kappa$ B upregulation, but combinations resulted in clear activation (except HOIL-1 with SHARPIN) and the highest one with all three proteins. By adding TRAIL and the several LUBAC components again around six to eightfold inductions could be shown in comparison to the overexpressed components without TRAIL. The combined overexpression of the LUBAC proteins together with TRAIL (except HOIL-1 and SHARPIN) significantly increased NF- $\kappa \mathrm{B}$ signaling in comparison to overexpressed LUBAC components alone.

Analyzing the phosphorylation state of $\mathrm{I} \kappa \mathrm{B} \alpha$ residuals, 32 and 36 upon TNF treatment as control, a strong 

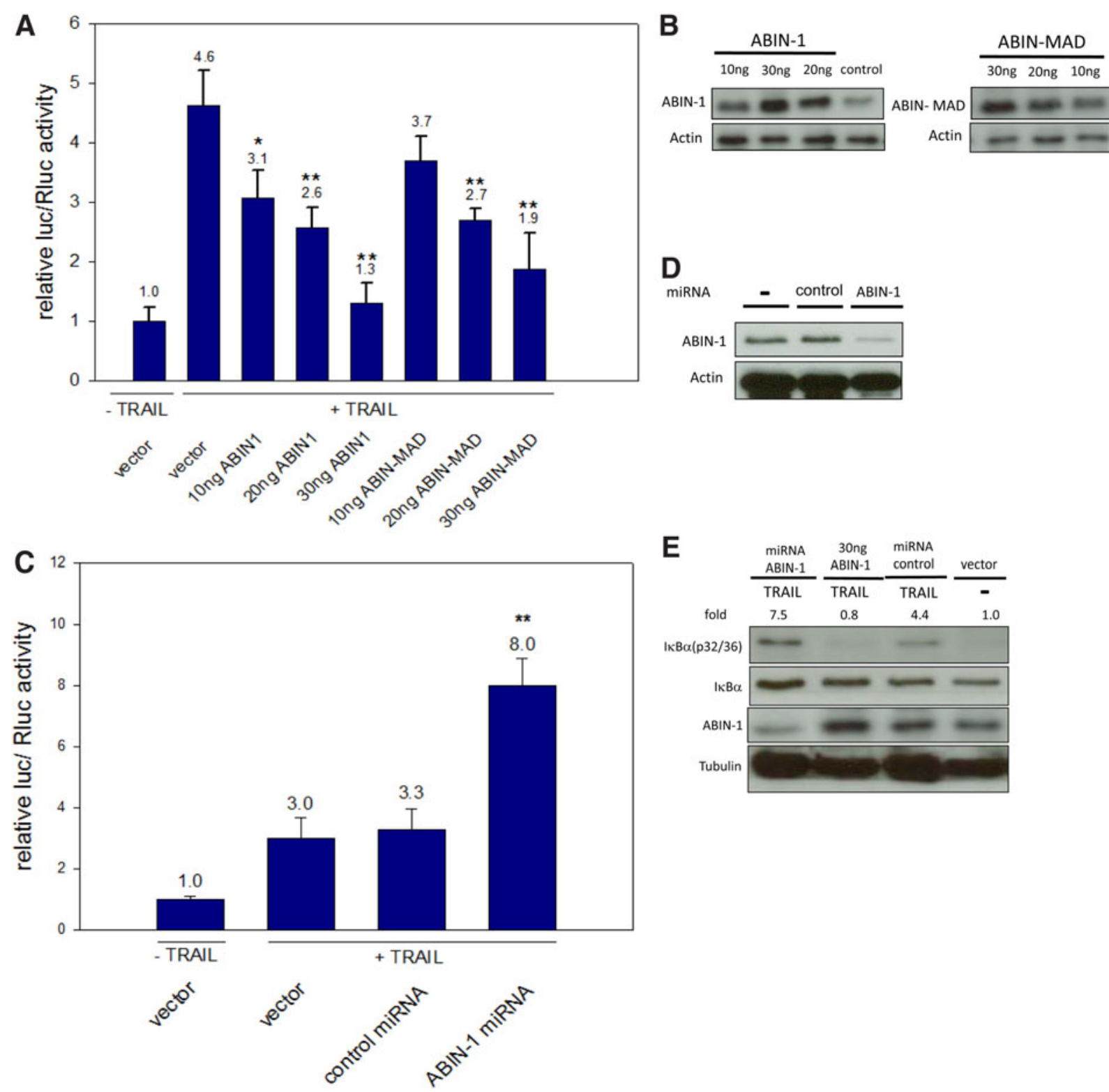

FIG. 1. $A B I N-1$ and $A B I N-M A D$ inhibit NF- $\kappa B$ signaling upon TRAIL treatment. $A B I N-1, A B I N-M A D$ plasmids (A), ABIN-1-targeting miRNA (C), or Bluescript vector as control $(\mathbf{A}, \mathbf{C})$ in combination with a firefly luciferase expressing NF- $\kappa$ B responsive reporter, and a Renilla luciferase expressing vector were cotransfected in HEK293 cells. After $48 \mathrm{~h}, 1000 \mathrm{ng} / \mathrm{mL}$ TRAIL was added, and the cells were lysed $24 \mathrm{~h}$ later to measure the relative luciferase levels. All values from relative firefly/Renilla luciferase assay represent three independent experiments with four $(\mathbf{A})$ or three $(\mathbf{C})$ replicants (per each construct and the bars indicate standard deviations. The statistical calculations comparing the transcriptional NF- $\kappa$ B inductions of Bluescript vector with different plasmid amounts of $A B I N-1, A B I N-M A D$, or ABIN-1 miRNA were done by Student's $t$-test (one asterisk indicates $p \leq 0.05$, two asterisks $p \leq 0.01)$. HEK293 cells were transfected with Bluescript vector (B, D, E), ABIN-1 (B, E), ABIN-MAD (B), ABIN miRNA (D, E), or control miRNA (D, E) and treated with TRAIL ( $1000 \mathrm{ng} / \mathrm{mL}$ for $50 \mathrm{~min}$ ) or left untreated. The expression levels of ABIN-1 (B, D, E), ABIN-MAD (B), phosphorylated $I \kappa B \alpha(32 / 36)$, unphosphorylated $I \kappa B \alpha$ (E) $\beta$-Actin (B, D), and $\alpha$-Tubulin proteins (E) were evaluated by western blotting. The expression level of $\alpha$ Tubulin (E) was evaluated after membrane stripping. Numbers indicate ratios of signal intensities of phosphorylated $\mathrm{I} \kappa \mathrm{B} \alpha(32 / 36)$ to unphosphorylated $\mathrm{I} \kappa \mathrm{B} \alpha$, normalized to the ratio of untreated cells (arbitrarily set to 1.0). For determination of intensities, the software Image Studio Lite was used. ABIN-1, A20 binding and inhibitor of NF-kappaB; ABIN-MAD, minimal active domain of ABIN; TRAIL, TNF-related apoptosis-inducing ligand. 
A

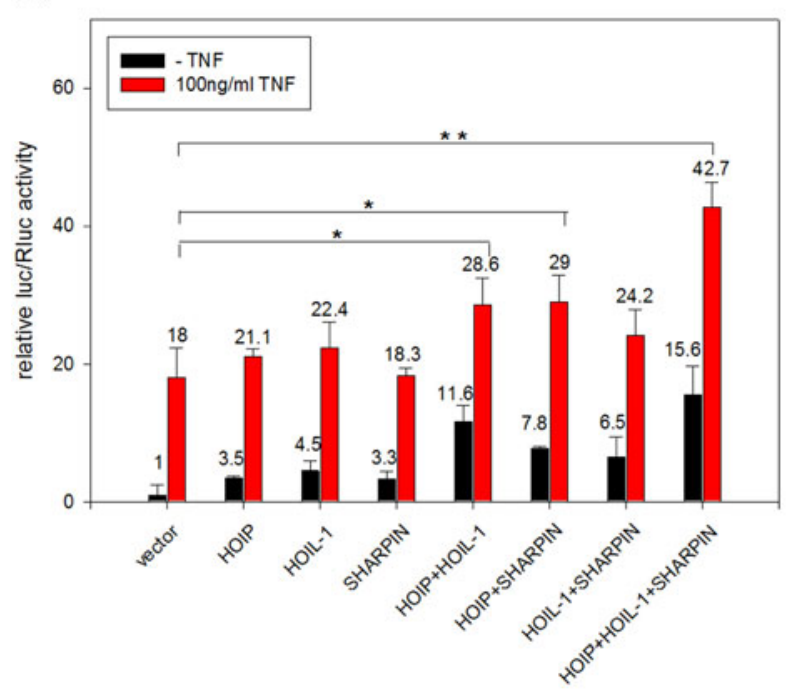

B

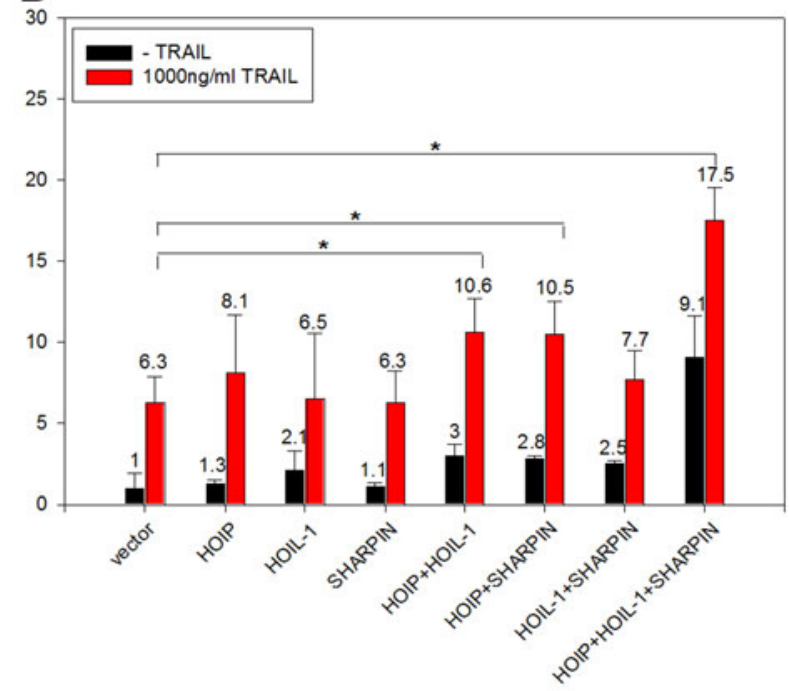

C

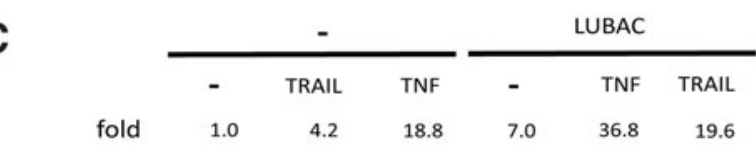

IкB $\alpha(p 32 / 36)$
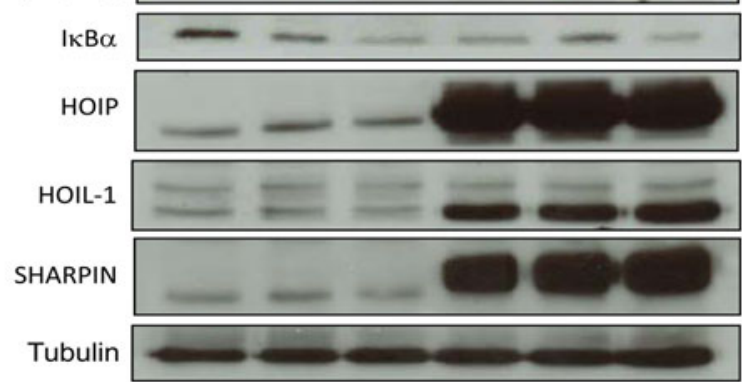

FIG. 2. LUBAC further increases NF- $\kappa B$ signaling upon TRAIL treatment. HEK293 cells were cotransfected with Bluescript vector or different combinations of HOIP-Myc, HA-HOIL-1, or SHARPIN expressing plasmids in combination with firefly luciferase expressing NF- $\kappa$ B responsive reporter and Renilla luciferase expressing construct and treated after $48 \mathrm{~h}$ with (A) TNF $(100 \mathrm{ng} / \mathrm{mL})$ or (B) TRAIL $(1000 \mathrm{ng} / \mathrm{mL})$ for further $24 \mathrm{~h}$ or left untreated to analyze the resulting relative luciferase activity. (C) HEK293 cells were transfected with Bluescript vector as a control or with LUBAC (HOIP-Myc, HA-HOIL-1, and FLAG-SHARPIN-containing plasmids) and treated with TNF ( $100 \mathrm{ng} / \mathrm{mL}, 30 \mathrm{~min})$ or TRAIL $(1000 \mathrm{ng} / \mathrm{mL}, 50 \mathrm{~min})$ or left untreated. The results of the relative firefly/Renilla luciferase assay are derived from three independent experiments with three replicants per each construct and the bars characterize standard deviations. One asterisk represents a significance level of $p \leq 0.05$ and two asterisks of $p \leq 0.01$ (The differences in NF- $\kappa \mathrm{B}$ inductions between vector and LUBAC components with TNF or TRAIL were determined by Student's $t$-test). The expression levels of LUBAC components and phosphorylated $I \kappa B \alpha(32 / 36)$ and unphosphorylated $I \kappa B \alpha$ proteins were evaluated by western blotting. The expression levels of $\alpha$-Tubulin and SHARPIN were analyzed after membrane stripping. Numbers indicate ratios of signal intensities of phosphorylated $I \kappa B \alpha(32 / 36)$ to unphosphorylated $I_{\kappa} B \alpha$, normalized to the ratio of untreated cells without overexpressed LUBAC components (arbitrarily set to 1.0). The determination of intensities was done by using the software Image Studio Lite. LUBAC, linear ubiquitin chain assembly complex. 
phosphorylation, and in case of TRAIL, a weak but clear phosphorylation of $\mathrm{I} \kappa \mathrm{B} \alpha$ was visible (Fig. 2C). The overexpression of LUBAC components resulted in a stronger $\mathrm{I} \kappa \mathrm{B} \alpha$ phosphorylation than in the experiments without LUBAC, even without TRAIL or TNF stimulation. Finally, the combination of TNF or TRAIL with LUBAC overexpression followed a clear increase of $\mathrm{I} \kappa \mathrm{B} \alpha$ phosphorylation.

Thus, we were able to show that LUBAC contributes to an upregulation of NF- $\kappa \mathrm{B}$ signaling upon TRAIL treatment. As a next step, we wanted to analyze whether the several LUBAC components do not just contribute but are required for this process. For demonstrating that again in combination with dual luciferase assay (including a NF- $\kappa$ B responsive reporter) and TNF/TRAIL treatment, five different SHARPIN, HOIL-1, and HOIPtargeting miRNAs were expressed, which should result in clear downregulations of NF- $\kappa \mathrm{B}$ signaling (for miRNAs sequences see Supplementary Data).

In first experiments, HEK293 cells were stimulated by TNF as control and the impact of differently expressed miRNAs for SHARPIN, HOIL-1, and HOIP knockdowns on NF- $\kappa$ B signaling were analyzed. Actually, by using miRNAs against SHARPIN (miRNA5), HOIL-1 (miRNA1, 2, 4), and HOIP (miRNA1, 4), a clear reduction of TNF-based NF- $\kappa$ B signaling was observed (Fig. 3A), confirming that LUBAC is essential for the NF- $\kappa$ B activation upon TNF treatment. The outstanding miRNAs did not show any NF- $\kappa$ B reduction (data not shown).

These experiments were then conducted using TRAIL as a stimulus with similar results (Fig 3B). Again the same miRNAs led to reductions in NF- $\kappa \mathrm{B}$ signaling.

To demonstrate the impact of downregulation of SHARPIN, HOIL-1, or HOIP on NF- $\kappa$ B signaling on protein level, the resulting phosphorylation state of $\mathrm{I} \kappa \mathrm{B} \alpha$ (Serine $\mathrm{p} 32 / 36)$ was analyzed again upon TNF or TRAIL treatment. In this context, by adding our control, TNF or TRAIL a clear increase, but only a weak or absent phosphorylation of $\mathrm{I} \kappa \mathrm{B} \alpha$, in case of HOIP (Fig. 3C), HOIL-1 (Fig. 3D), or SHARPIN (Fig. 3E) downregulation was shown. These results clearly indicate that in HEK293 cells, all the LUBAC components together are crucial for basal and TRAIL- as well as TNF-stimulated NF- $\kappa$ B induction, but HOIP seems to play a most important role (similar as it was shown with TNF).

\section{Discussion}

In this study, we were able to show that ABIN-1 as well as ABIN-1-MAD inhibit TRAIL-based NF- $\kappa \mathrm{B}$ signal- ing. This finding is supported by experiments in HEK293 and HeLa (unpublished data) cells, in which downregulation of ABIN-1 by miRNA leads to significant higher TRAIL-based NF- $\kappa$ B transcriptional activity. The ability of ABIN-1 to inhibit this pathway after induction with TNF has already been shown previously. ${ }^{25} \mathrm{ABIN}-1$ usually interacts with the deubiquitinase A20 and binds to polyubiquitylated NEMO (IKK $\gamma)$.

The exact role of A20 as key inhibitor of TRAILinduced NF- $\kappa \mathrm{B}$ signaling working as deubiquitinase or as a binder of linear ubiquitylation is still under debate. ${ }^{22}$ Considering the potential results of this study that ABIN-1 may inhibit NF- $\kappa$ B signaling even without A20 could mean that ABIN-1 may work as binder of the linear ubiquitylation chains and A20 primarily contributes as deubiquitinase for K63-linked chains to achieve NF- $\kappa \mathrm{B}$ signaling downregulation. But the exact function of ABIN-1 has to be evaluated in more substantial experiments.

In addition, in this study, we assessed the influence of the LUBAC components HOIL-1, HOIP, and SHARPIN on NF- $\kappa$ B induction levels. In overexpression experiments, we showed that LUBAC is able to potentiate NF- $\kappa$ B signaling upon TRAIL application in dual luciferase and analyzing the $\mathrm{I} \kappa \mathrm{B} \alpha$ phosphorylation status in western blotting assays. Finally, in dual luciferase assays as well as in western blotting assays, we demonstrated that LUBAC components are required to activate this pathway by using specific miRNAs against each component, resulting in clear NF- $\kappa \mathrm{B}$ downregulations and reduced phosphorylation of $\mathrm{I} \kappa \mathrm{B} \alpha$ on protein level. Hence, we conclude that LUBAC is critically involved in the canonical activation of NF- $\kappa \mathrm{B}$ signaling.

The involvement of LUBAC on NF- $\kappa$ B induction has been shown in numerous studies supporting the theory that LUBAC seems to be important for canonical NF$\kappa \mathrm{B}$ activity in general not only in context of receptors. ${ }^{27,29}$ But the exact mechanism of NF- $\kappa$ B upregulation in combination with TRAIL leading to p65/p50 activation is not yet entirely clear. It seems to be that upon Caspase- 8 activation a NF- $\kappa \mathrm{B}$ activation complex is formed consisting of ubiquitylated RIP1, TAK1, TAB1/2, and the kinases IKK $\alpha$, IKK $\beta$, and IKK $\gamma$ (NEMO). ${ }^{7,19,20,29}$ Part of this process is the phosphorylation of IKK $\alpha$ and/or IKK $\beta$ to achieve the phosphorylation of $\mathrm{I} \kappa \mathrm{B} \alpha(\mathrm{p} 32 / 36)$ and the activation of $\mathrm{p} 65 / \mathrm{p} 50 .^{19,20,38,39}$

Looking at the results of this study, SHARPIN, HOIL-1, and HOIP also seem to be involved in the activation of NF- $\kappa \mathrm{B}$ upstream of the phosphorylation of $\mathrm{I} \kappa \mathrm{B} \alpha$ in HEK293 cells as shown in other cell lines. ${ }^{29}$ 

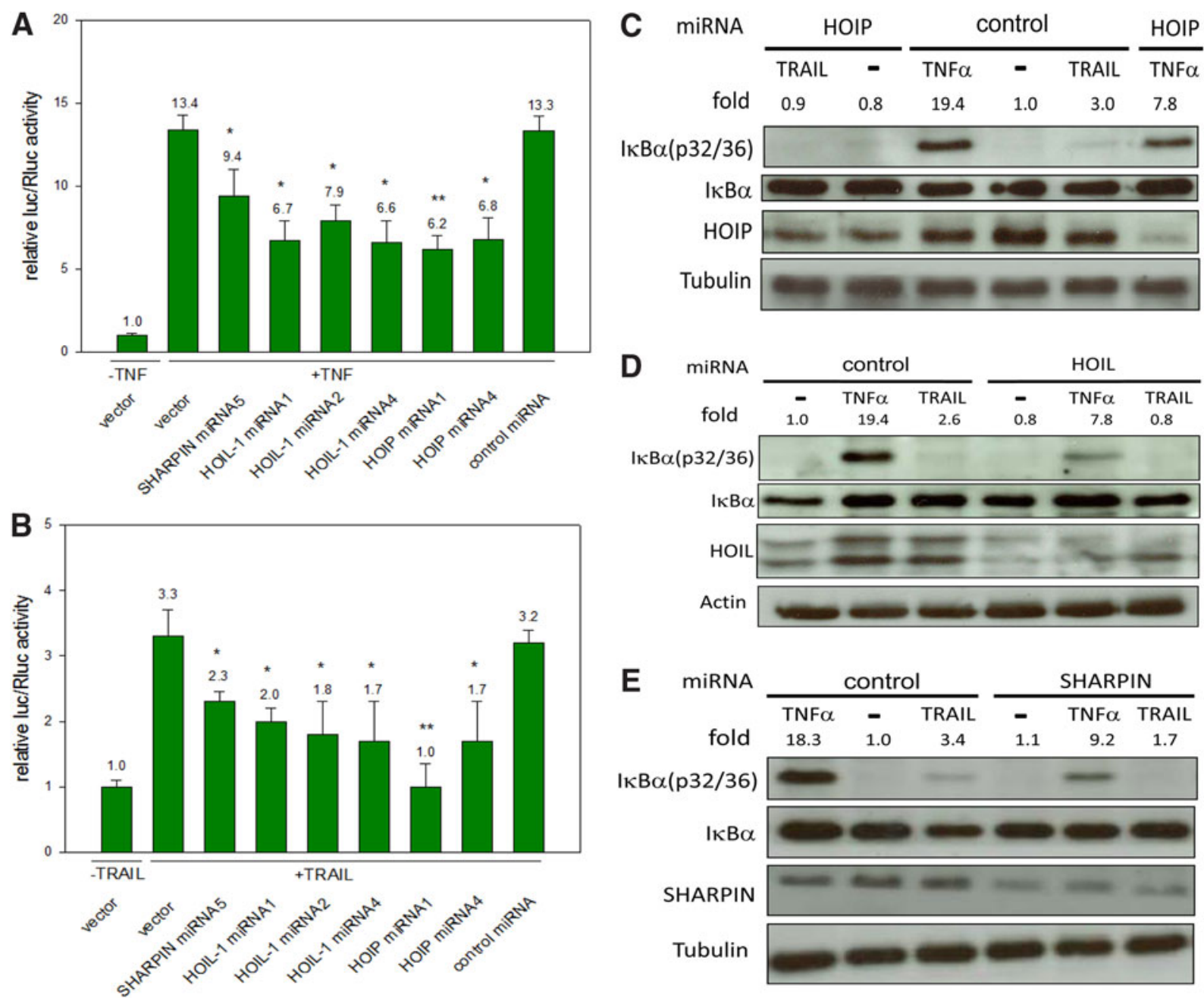

FIG. 3. Downregulations of HOIP, HOIL-1, or SHARPIN decrease TRAIL-based NF- $\kappa$ B signaling. Various HOIP, HOIL-1, or SHARPIN-targeting miRNAs, a control miRNA, or Bluescript vector were cotransfected with the firefly luciferase expressing NF- $\kappa \mathrm{B}$ responsive reporter and the Renilla luciferase expressing vector to evaluate the resulting relative luciferase expressing levels after $24 \mathrm{~h}$ in untreated or (A) TNF- $(100 \mathrm{ng} / \mathrm{mL}$, $48 \mathrm{~h}$ after transfection) or (B) TRAIL ( $1000 \mathrm{ng} / \mathrm{mL}, 48 \mathrm{~h}$ after transfection)-treated HEK293 cells. The results of the relative firefly/Renilla luciferase assay are derived from three independent experiments with three replicants per each construct and the bars characterize standard deviations. One asterisk represents a significant level of $p \leq 0.05$ and two asterisks of $p \leq 0.01$ (The differences in NF- $\kappa \mathrm{B}$ inductions between vector and LUBAC components with TNF or TRAIL were determined by Student's $t$-test). HEK293 cells were transfected with Bluescript vector, (C) HOIP miRNA1, (D) HOIL-1 miRNA1, or (E) SHARPIN miRNA and treated with TNF (100 ng/mL for $30 \mathrm{~min}$ ) or TRAlL $(1000 \mathrm{ng} / \mathrm{mL}$ for $50 \mathrm{~min})$ or left untreated. The expression levels of HOIP, HOIL-1, SHARPIN, phosphorylated $I_{\kappa} B \alpha(32 / 36)$, unphosphorylated $I_{\kappa} B \alpha$, and $\alpha$-Tubulin were analyzed by western blotting. The expression levels of $\beta$-Actin (D) and SHARPIN (E) were evaluated after membrane stripping. Numbers indicate ratios of signal intensities of phosphorylated $I \kappa B \alpha(32 / 36)$ to unphosphorylated $\mid \kappa B \alpha$, normalized to the ratio of untreated cells with control miRNA (arbitrarily set to 1.0). For determination of intensities, the software Image Studio Lite was used. 
Possibly LUBAC acts in a similar way as it is doing upon TNF signaling by stabilizing the IKK/TAK1 complex to reach efficient NF- $\kappa \mathrm{B}$ induction. However, more experiments need to be performed to demonstrate the involvement of linear ubiquitylation and a possible stabilization of this complex. Also, its assembly and its exact position working not downstream or upstream need to be examined.

However, for future applications especially for possible cancer treatments, the finding that LUBAC as well as ABIN-1 are strongly involved in regulation of TRAILbased NF- $\kappa$ B signaling in HEK293 cells could lead to new therapeutic options. Therapies inhibiting the function of LUBAC, and therefore the TRAIL-induced "canonical" NF- $\kappa$ B activation creating a proapoptotic instead of an antiapoptotic state in cancer cells, is conceivable. Overall, our experiments indicate that ABIN1 and ABIN-MAD as well as of LUBAC and its components are involved in regulation of TRAIL-induced NF- $\kappa$ B signaling pathway in HEK293 cells.

\section{Conclusions}

Our results show that overexpression of LUBAC components leads to a clear upregulation of TNF as well as TRAIL-induced NF- $\kappa$ B signaling in HEK293 cells. In addition, downregulations of each LUBAC component result in a significant decrease of TNF and TRAIL-induced NF- $\kappa \mathrm{B}$ signaling, respectively. In contrary, overexpression of $\mathrm{ABIN}-1$ or ABIN-MAD (not able to bind to deubiquitinase A20) leads to significantly lower and downregulation of ABIN-1 and leads to significantly higher TRAIL-induced NF- $\kappa \mathrm{B}$ signaling. All these results clearly indicate that LUBAC is critically involved in initiation and ABIN-1 potentially works as an antagonist of TRAIL-induced NF- $\kappa$ B signaling in HEK293 cells.

Therefore, cancer therapies inhibiting the function of LUBAC and the TRAIL-induced "canonical" NF$\kappa \mathrm{B}$ activation, making them more sensitive for TRAIL treatment, would be a promising approach in case of resistance formation.

\section{Acknowledgments}

We thank Volker Wachek for providing the laboratories.

This work was supported in part by a grant from the Austrian Science Funds (FWF) SFB54-P04.

\section{Authors' Contributions}

All the authors participated in the design of the studies, analysis of the data, and review of the article. S.D. designed the study and conducted the experiments.
S.D. and C.S. wrote the article. All authors read and approved the final article.

\section{Author Disclosure Statement}

The authors declare that they have no competing interest.

\section{References}

1. Varfolomeev E, Goncharov T, Fedorova AV, et al. c-IAP1 and c-IAP2 are critical mediators of tumor necrosis factor alpha (TNFalpha)-induced NFkappaB activation. J Biol Chem. 2008;283:24295-24299.

2. Vucic D, Dixit VM, Wertz IE. Ubiquitylation in apoptosis: a posttranslational modification at the edge of life and death. Nat Rev Mol Cell Biol. 2011;12:439-452.

3. Kim KW, Kim BJ, Chung CW, et al. Caspase cleavage product lacking amino-terminus of IkappaBalpha sensitizes resistant cells to TNF-alpha and TRAIL-induced apoptosis. J Cell Biochem. 2002;85:334-345.

4. Rothe M, Sarma V, Dixit VM, et al. TRAF2-mediated activation of NF-kappa B by TNF receptor 2 and CD40. Science. 1995;269:1424-1427.

5. Micheau O, Tschopp J. Induction of TNF receptor I-mediated apoptosis via two sequential signaling complexes. Cell. 2003;114:181-190.

6. Mahoney DJ, Cheung $\mathrm{HH}$, Mrad RL, et al. Both CIAP1 and CIAP2 regulate TNFalpha-mediated NF-kappaB activation. Proc Natl Acad Sci U S A. 2008;105:11778-11783.

7. Bertrand MJ, Milutinovic S, Dickson KM, et al. CIAP1 and CIAP2 facilitate cancer cell survival by functioning as E3 ligases that promote RIP1 ubiquitination. Mol Cell. 2008;30:689-700.

8. Haas $\mathrm{TL}$, Emmerich $\mathrm{CH}$, Gerlach B, et al. Recruitment of the linear ubiquitin chain assembly complex stabilizes the TNF-R1 signaling complex and is required for TNF-mediated gene induction. Mol Cell. 2009;36:831-844.

9. Gerlach B, Cordier SM, Schmukle AC, et al. Linear ubiquitination prevents inflammation and regulates immune signalling. Nature. 2011;471:591596.

10. Ikeda F, Deribe YL, Skanland SS, et al. SHARPIN forms a linear ubiquitin ligase complex regulating NF-kappaB activity and apoptosis. Nature. 2011;471:637-641.

11. Tokunaga $F$, Nakagawa T, Nakahara M, et al. SHARPIN is a component of the NF-kappaB-activating linear ubiquitin chain assembly complex. Nature. 2011;471:633-636.

12. Yeh WC, Itie A, Elia AJ, et al. Requirement for Casper (c-FLIP) in regulation of death receptor-induced apoptosis and embryonic development. Immunity. 2000;12:633-642.

13. Krueger A, Schmitz I, Baumann S, et al. Cellular FLICE-inhibitory protein splice variants inhibit different steps of caspase-8 activation at the CD95 death-inducing signaling complex. J Biol Chem. 2001;276:20633-20640.

14. Budd RC, Yeh WC, Tschopp J. cFLIP regulation of lymphocyte activation and development. Nat Rev Immunol. 2006;6:196-204.

15. Guicciardi ME, Gores GJ. Life and death by death receptors. FASEB J. 2009; 23:1625-1637.

16. Wertz IE, Dixit VM. Regulation of death receptor signaling by the ubiquitin system. Cell Death Differ. 2010;17:14-24.

17. Varfolomeev $E$, Maecker $H$, Sharp D, et al. Molecular determinants of kinase pathway activation by Apo2 ligand/tumor necrosis factorrelated apoptosis-inducing ligand. J Biol Chem. 2005;280:4059940608.

18. Jin Z, El-Deiry WS. Distinct signaling pathways in TRAIL- versus tumor necrosis factor-induced apoptosis. Mol Cell Biol. 2006;26:8136-8148.

19. Chaudhary PM, Eby MT, Jasmin A, et al. Activation of the NF-kappaB pathway by caspase 8 and its homologs. Oncogene. 2000;19: 4451-4460.

20. Geserick P, Hupe M, Moulin M, et al. RIP-in CD95-induced cell death: the control of alternative death receptors pathways by cIAPs. Cell Cycle. 2010;9:2689-2691.

21. Falschlehner $\mathrm{C}$, Emmerich $\mathrm{CH}$, Gerlach $\mathrm{B}$, et al. TRAIL signalling: decisions between life and death. Int J Biochem Cell Biol. 2007;39:1462-1475.

22. Lafont $E$, Hartwig T, Walczak H. Paving TRAIL's path with ubiquitin. Trends Biochem Sci. 2018:43:44-60.

23. Kumar A, Takada Y, Boriek AM, et al. Nuclear factor-kappaB: its role in health and disease. J Mol Med (Berl). 2004;82:434-448. 
24. Mauro C, Pacifico F, Lavorgna $A$, et al. ABIN-1 binds to NEMO/IKKgamma and co-operates with A20 in inhibiting NF-kappaB. J Biol Chem. 2006;281:18482-18488.

25. Wagner S, Carpentier I, Rogov V, et al. Ubiquitin binding mediates the NF-kappaB inhibitory potential of ABIN proteins. Oncogene. 2008; 27:3739-3745.

26. Tokunaga F, Sakata S, Saeki Y, et al. Involvement of linear polyubiquitylation of NEMO in NF-kappaB activation. Nat Cell Biol. 2009;11: 123-132.

27. Tokunaga F, Iwai K. Linear ubiquitination: a novel NF-kappaB regulatory mechanism for inflammatory and immune responses by the LUBAC ubiquitin ligase complex. Endocr J. 2012;59:641-652.

28. Hayden MS, Ghosh S. Signaling to NF-kappaB. Genes Dev. 2004;18: 2195-2224.

29. Lafont E, Kantari-Mimoun C, Draber $P$, et al. The linear ubiquitin chain assembly complex regulates TRAIL-induced gene activation and cell death. EMBO J. 2017;36:1147-1166.

30. Stepanenko AA, Dmitrenko VV. HEK293 in cell biology and cancer research: phenotype, karyotype, tumorigenicity, and stress-induced genome-phenotype evolution. Gene. 2015;569:182-190.

31. Shen C, Gu M, Song C, et al. The tumorigenicity diversification in human embryonic kidney 293 cell line cultured in vitro. Biologicals. 2008;36:263268.

32. Harper N, Farrow SN, Kaptein A, et al. Modulation of tumor necrosis factor Apoptosis-inducing Ligand-induced NF- $\kappa$ B Activation by Inhibition of Apical caspases. J Biol Chem. 2001;276:34743-34752.

33. Clarke $P$, Meintzner SM, Moffitt LA, et al. Two distinct phases of virusinduced nuclear factor $\kappa \mathrm{B}$ regulation enhance tumor necrosis factorrelated apoptosis-inducing ligand-mediated apoptosis in virus-infected cells. J Biol Chem. 2003;278:18092-18100.

34. Shetty S, Gladden JB, Henson ES, et al. Tumor necrosis factor-related apoptosis inducing ligand (TRAIL) up-regulates death receptor 5 (DR5) mediated by NFkappaB activation in epithelial derived cell lines. Apoptosis. 2002;7:413-420.

35. Gao J, Wang D, Liu D, et al. Tumor necrosis factor-related apoptosisinducing ligand induces the expression of proinflammatory cytokines in macrophages and re-educates tumor-associated macrophages to an antitumor phenotype. Mol Biol Cell. 2015;26:3178-3189.

36. Song $H$, Rothe $M$, Goeddel DV. The tumor necrosis factor-inducible zinc finger protein A20 interacts with TRAF1/TRAF2 and inhibits NF-kB activation. Proc Natl Acad Sci U S A. 1996;93:6721-6725.

37. Inoue $\mathrm{M}$, Kamada $\mathrm{H}$, Abe $\mathrm{Y}$, et al. Aminopeptidase $\mathrm{P} 3$, a new member of the TNF-TNFR2 signaling complex, induces phosphorylation of JNK1 and JNK2. J Cell Sci. 2015;128:656-669.
38. Diessenbacher $P$, Hupe $M$, Sprick MR, et al. NF-kappaB inhibition reveals differential mechanisms of TNF versus TRAIL-induced apoptosis upstream or at the level of caspase-8 activation independent of CIAP2. J Invest Dermatol. 2008;128:1134-1147.

39. Lluis JM, Nachbur U, Cook WD, et al. TAK1 is required for survival of mouse fibroblasts treated with TRAIL, and does so by NF-kappaB dependent induction of cFLIPL. PLoS One. 2010;5:e8620.

Cite this article as: Dorn $S$, Schoergenhofer $C$, Krainer $M$, Müller $M$, Jilma B (2018) LUBAC and ABIN-1 modulate TRAIL-based NF- $\kappa B$ induction in human embryonic kidney 293 cells, BioResearch Open Access 7:1, 81-89, DOI: 10.1089/biores.2018.0006.

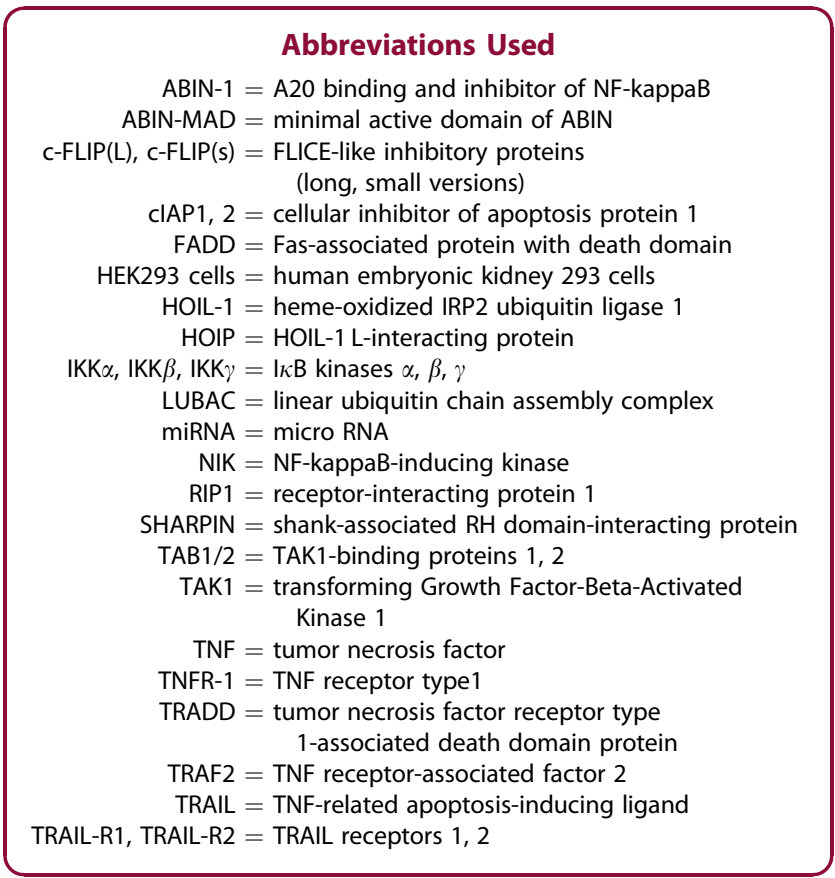

